Article

\title{
Dihydropyridine Enhances the Antioxidant Capacities of Lactating Dairy Cows under Heat Stress Condition
}

\author{
Meng-Fei Yu ${ }^{1,2}$ (D), Xin-Mao Zhao ${ }^{2}$, Hang Cai ${ }^{2}$, Jian-Ming Yi ${ }^{2, *}$ and Guo-Hua Hua ${ }^{2, *}$
}

1 Hubei Provincial Key Laboratory for Protection and Application of Special Plant Germplasm in Wuling Area of China, College of Life Sciences, South-Central University for Nationalities, $182 \mathrm{Min} \mathrm{Zu}$ Da Dao, Wuhan 430074, China; 2011093@mail.scuec.edu.cn

2 Key Laboratory of Agricultural Animal Genetic, Breeding, and Reproduction for Ministry of Education, College of Animal Science and Technology, Huazhong Agricultural University, Wuhan 430070, China; alabaster1001@163.com (X.-M.Z.); caihang1001@126.com (H.C.)

* Correspondence: yijm@mail.hzau.edu.cn (J.-M.Y.); huaguohua09@gmail.com (G.-H.H.); Tel.: 86-27-8728-0640 (J.-M.Y.); 86-27-8751-5280 (G.-H.H.)

Received: 26 August 2020; Accepted: 21 September 2020; Published: 5 October 2020

Simple Summary: Additives contribute to improving the health of dairy cows, enhancing antioxidative capacities, and/or increasing milk production, etc. To alleviate the harmful effects of heat stress on dairy cows, a few feed additives studies have been conducted. Dihydropyridine has been used as a feed additive in dairy cow diets. However, the underlying mechanisms of its beneficial effects still remain unclear. In the present study, dairy cows were randomly divided into a control group and a dihydropyridine treatment group under heat stress in summer. The rumen and blood samples of dairy cows were collected to determine the changes in their antioxidative capacities. Meanwhile, the effects of dihydropyridine on ruminal microbial communities were also analyzed. Our data demonstrated that dihydropyridine enhanced the antioxidative capacities of dairy cows under heat stress conditions.

\begin{abstract}
Heat stress (HS), a nonspecific response to environmental heat, can seriously affect dairy cow health. Feed additives may alleviate HS in dairy cows by improving rumen fermentation efficacy, stimulating feed consumption, enhancing vasodilation, and/or improving antioxidant capacity. The temperature-humidity index (THI) indicates that spring is a non-HS season, and summer is an HS season. HS results in the decrease in dairy cow antioxidant capacities. Our results indicated the decrease in superoxide dismutase (SOD), glutathione peroxidase (GSH-Px), catalase (CAT), and total antioxidation (T-AOC) levels and the increase in malondialdehyde (MDA) level during HS season. Meanwhile, antioxidant indexes (SOD, GSH-Px, and T-AOC) were positively correlated with milk yield $(p<0.01)$, whereas MDA exhibited a significant negative correlation with milk yield $(p<0.05)$. In addition, the effects of dihydropyridine (DHP) on antioxidant capacity and ruminal microbial communities in dairy cows under HS were investigated. During summer, dairy cows were randomly assigned into two groups under HS, including a standard diet (S-ND) group and standard diet with 3 g/day/cow DHP (S-D) group. DHP treatment significantly restored SOD and GSH-Px levels under HS. Denaturing gradient gel electrophoresis results indicated that the DHP altered ruminal bacterial community mainly composed Proteobacteria and Firmicutes in dairy cows under HS. Our results suggest that DHP can enhance the antioxidant abilities of dairy cows with favorable effects on ruminal microbial communities under HS, further alleviating HS on dairy cows.
\end{abstract}

Keywords: antioxidation; dihydropyridine; dairy cow; heat stress; ruminal bacterial community 


\section{Introduction}

Stress is the physical responses of animals to external and internal stimuli. Various stresses, such as oxidation and heat, can result in serious stress responses in dairy cows. For example, the primary reason for reproductive diseases such as retained placenta, endometritis, acute/chronic mastitis was oxidative stress [1]. Heat stress (HS) in dairy cows is a nonspecific response to the hot and humid environment, which exerts adverse impacts on the performance and physiological functions of the cows [2,3]. Lactating cows are more sensitive to the HS, which is attributed to their physiological characteristics and special nutritional requirements [4]. In turn, HS can stimulate the release of endocrine hormones which can damage the function of the immune system and increase morbidity. HS can cause serious problems, such as health damage and milk yield decrease.

Daily metabolic activities in dairy cows produce a large number of free radicals and other bioactive substances [5]. The production and elimination of these radicals and bioactive substances are kept in a balanced status by the antioxidant systems of the dairy cows. This balance can be interrupted by many detrimental factors such as diseases, oxidative stress, HS etc. The interrupted balance can be monitored by measuring the antioxidative capacities of serum and rumen fluids. The antioxidant capacity of dairy cows is usually evaluated by five parameters, namely, total antioxidation (T-AOC), superoxide dismutase (SOD), Glutathione peroxidase (GSH-Px), catalase (CAT), and malondialdehyde (MDA), which refer to the abilities of total antioxidation, eliminating free radicals, cleaning up peroxide, eliminating $\mathrm{H}_{2} \mathrm{O}_{2}$, and ability of lipid peroxidation, respectively. Among them, SOD, GSH-Px, and CAT function coordinately to eradicate the intracellular harmful substances and protect the cells. HS can interrupt the expressions and functions of these enzymes, which in turn results in the accumulation of superoxide anion radicals. The increased superoxide anion radicals lead to the formation of MDA which induces cell death by breaking DNA. In general, relatively high levels of T-AOC, SOD, GSH-Px, and CAT, and a relatively low value of MDA represent a better antioxidant capacity in dairy cows. These five antioxidant indexes in blood and/or ruminal fluids are usually used to evaluate the stress status of dairy cows [6].

Dihydropyridine (DHP) is a type of $\mathrm{Ca}^{2+}$ channel antagonist, which can inhibit $\mathrm{Ca}^{2+}$ influx into the cytoplasm and decrease the concentration of cytoplasmic $\mathrm{Ca}^{2+}$. DHP is widely used as a therapeutic agent for diseases such as myocardial ischemia [7], hypertension [8], and renal diseases [9]. Additionally, DHP has been used as an additive in animal diets due to its antioxidant ability to protect oil, vitamin A, beta-carotene from oxidation [10]. Meanwhile, DHP can alter the levels of hormones in the serum, which is beneficial for the promotion of the growth of animals, enhancing reproductive ability, and increasing milking capacity. DHP can be metabolized without toxic effects in many species, such as pigs and chickens [11,12]. These evidences indicate DHP is a good feed additive candidate for alleviating the harmful responses induced by HS. However, the effects of DHP diet on ruminal antioxidant capacity and the underlying mechanisms remain unclear.

In this study, we investigated the effects of DHP diet on the alteration in the structure and components of ruminal microbes (bacteria, protozoa, archaea, and fungi) in lactating dairy cows. Moreover, the effects of DHP on the antioxidant capacity, such as SOD, GSH-Px, T-AOC, and MDA in the serum and ruminal fluids of dairy cows were also analyzed. The elucidation of the effects of DHP in dairy cows will be helpful in improving cows' health and production performance under HS.

\section{Materials and Methods}

\subsection{Animals and Ethical Statement}

All animal experiments were approved by the Huazhong Agricultural University animal care and use committee. All experimental protocols were also approved by the committee mentioned above and performed in accordance with the relevant guidelines and regulations (Approval No: YJM-201001). 


\subsection{Determination of Anti-Oxidative Indexes}

To determine anti-oxidative indexes under non-HS and HS conditions, a total of forty healthy Chinese Holstein cows were chosen. These dairy cows were all in the mid-lactation (124.8 \pm 13.4 days) period with similar parity $(2.8 \pm 0.7)$, body weight $(513.0 \pm 6.0 \mathrm{~kg})$ and milking abilities $(37.1 \pm 2.5 \mathrm{~kg})$. All cows were fed with standard diet from April 1st to July 14th. The standard diets were formulated to meet the feeding standards of China Holstein cows (NY/T 34-2004, Table 1). All cows were provided with ad libitium intake at 12-h intervals to meet nutritional requirements. On April 15th and July 14th, blood samples were collected from all dairy cows. Five antioxidant indexes including SOD, GSH-Px, T-AOC, MDA, and CAT were detected from the serum samples. Meanwhile, the correlations between antioxidant indexes and milk yield were analyzed.

Table 1. Formulation and nutritional ingredients of standard diet.

\begin{tabular}{cccc}
\hline Diet Components & Formulation (\%) & Nutritional Ingredients & Content (\%) \\
\hline Corn silage & 55.6 & Dry matter (DM, \%) & 51.4 \\
Peanut hay & 13.9 & Dry matter intake (DMI, kg/d) & 18.5 \\
Corn & 15.6 & Net energy for lactation (NEL, MJ/d) & 29.7 \\
Wheat bran & 6.1 & Crude protein (CP, \%) & 15.37 \\
Soybean meal & 4.6 & Acid detergent fiber (ADF, \%) & 24.09 \\
Cotton seed meal & 2.4 & Neutral detergent fiber (NDF, \%) & 37.42 \\
CaHPO $_{4}$ & 0.6 & Calcium (Ca, \%) & 0.91 \\
NaHCO $_{3}$ & 0.3 & Phosphorus (P, \%) & 0.48 \\
Premix & 0.9 & & \\
Total & 100.0 & & \\
\hline
\end{tabular}

Note: Nutritional ingredients were based on the content of DM. The contents of CP, ADF, DNF, Ca and P were measured, while the content of NEL was calculated.

\subsection{Detection of HS Using Temperature-Humidity Index (THI) Method}

Dairy cows were housed in a semi-open barn with ventilation fans and without sprinkler facilities. The HS level of these dairy cows were evaluated by monitoring the changes in ambient temperature and humidity using six dry-wet bulb hygrometers (Model, TAL-2, Beijing Kawe Meters Co., Ltd., Beijing, China). Three hygrometers were hung $2 \mathrm{~m}$ above the aisle and the beds indoors, while the other three hygrometers were hung outdoors. During the experimental period, the values were recorded at 08:00, 14:00, and 20:00. THI was calculated using the following formula: $\mathrm{THI}=0.72 \times(\mathrm{Td}+\mathrm{Tw})+40.6$, where $\mathrm{Td}$ and $\mathrm{Tw}$ indicated dry bulb temperature and wet bulb temperature in ${ }^{\circ} \mathrm{C}$, respectively [13].

\subsection{DHP Supplement Experiment}

Compared to the milk yield in April, the cows with milk yield decreased $>50 \%$ in July were considered as heat-sensitive cows. To evaluate the effects of DHP on the antioxidant capacities and ruminal microbes in mid-lactation dairy cows, the selected twenty heat-sensitive cows were randomly divided into two groups: a control group and an experimental group $(n=10)$. The cows in the control group (S-ND) were fed with the standard diet (Table 1), while the cows in the experimental group (S-D) were fed with the standard diet containing 3 g/day/cow DHP from 15 July to 30 July according to the Veterinary Drug Quality Standards 2003 edition [14]. DHP was first mixed with a small amount of concentrate, followed by an expanding mixture with all other feed. The effects of DHP on the antioxidant capacities and the composition of ruminal microbes in the dairy cows were analyzed. The blood samples were collected on 30 July for the determination of antioxidant indexes (SOD, GSH-Px, T-AOC, MDA, and CAT). In addition, ruminal fluids were collected on 30 July and 31 July and stored at $-20{ }^{\circ} \mathrm{C}$ for the analysis of the composition of ruminal microbes. 


\subsection{Blood Sample Collection}

On July 30, whole blood was collected as previously described with some modifications [15]. Ten milliliters of whole blood was collected at 10:00 a.m. via tail vein. After being kept on ice for 30 $\mathrm{min}$, the blood was centrifuged at $5000 \mathrm{rpm}$ for $5 \mathrm{~min}$ to isolate the serum. The obtained serum was stored at $-20^{\circ} \mathrm{C}$, for subsequent experiments.

\subsection{Ruminal Fluids Collection}

Ruminal fluids were collected as previously described elsewhere with some modifications $[16,17]$. Briefly, $30 \mathrm{~mL}$ ruminal fluids were collected using rumenocentesis. These ruminal fluids were collected at 13:00 on 30 July and 07:00 and 10:00 on 31 July and stored at $-20{ }^{\circ} \mathrm{C}$ for further experiments. These samples were to be used to analyze the contents of SOD, GSH-Px, T-AOC, MDA, and CAT, in the blood and ruminal fluids, respectively.

\subsection{Detection of Antioxidant Status of Dairy Cows}

The contents of GSH-Px, SOD, CAT, T-AOC, and MDA in the serum and ruminal fluids were measured using five different kits, namely, the GSH-Px assay kit (Cat.: A005), SOD assay kit (Cat.: A001-3), T-AOC assay kit (Cat.: A015-2), CAT assay kit (Cat.: A007-1-1), and the MDA assay kit (Cat.: A003-1), according to the manufacturer's instructions, respectively. All these kits were commercially purchased from by Nanjing Jiancheng Bioengineering Institute (Nanjing, China).

\subsection{DNA Extraction}

The genomic DNA of microbiota in the rumen fluids was extracted using a DNA isolation kit (Cat.: AU2001, Bioteke, Beijing, China) according to the manufacturer's instructions. The purity and concentration were determined by a spectrophotometer (Nanodrop 2000, Thermo Scientific, Wilmington, DE, USA). The DNA samples were stored at $-20^{\circ} \mathrm{C}$ for the further processing.

\subsection{Real-Time PCR}

The genomic DNA mentioned above was used as the template to amplify the 16S rRNA V6-V8 region. All primers were synthesized by Sangon Biotech (Shanghai) Co., Ltd. (Shanghai, China). Detailed information of the primers (total bacteria, fungi, protozoa, Methanogens, B. fibrisolvens, C.proteoclasticum, F. succinogenes, $R$. albus, and R. flavefaciens) is shown in Table 2. The PCR system included $12.5 \mu \mathrm{L}$ SYBR ${ }^{\circledR}$ Green Real-Time PCR MasterMix (St. Louis, MO, USA), $0.5 \mu \mathrm{L}$ forward primer $(10 \mathrm{mM}), 0.5 \mu \mathrm{L}$ reverse primer $(10 \mathrm{mM}), 1 \mu \mathrm{L}$ DNA template, and $9.5 \mu \mathrm{L}$ sterile deionized water. The procedures for Real-time PCR were as follows: pre-denaturalization for $3 \mathrm{~min}$ at $95.0^{\circ} \mathrm{C}$, 40 cycles of denaturalization for $30 \mathrm{~s}$ at $95.0^{\circ} \mathrm{C}$, annealing for $30 \mathrm{~s}$ at $60.0^{\circ} \mathrm{C}$, and extension for $30 \mathrm{~s}$ at $72.0^{\circ} \mathrm{C}$, followed by extension for $7 \mathrm{~min}$ at $72.0^{\circ} \mathrm{C}$. The relative contents of the above-mentioned eight microbes in ruminal fluids were calculated using total bacteria as a reference, as previously described [18] or designed using NCBI primer-Blast (www.ncbi.nlm.nih.gov/tools/primer-blast/). 
Table 2. Primers for real-time PCR assay (used in this study).

\begin{tabular}{|c|c|c|c|}
\hline Target Species & Primer & Sequence $\left(5^{\prime}-3^{\prime}\right)$ & Reference \\
\hline \multirow{2}{*}{ Total bacteria } & $\mathrm{F}$ & CGGCAACGAGCGCAACC & \multirow{2}{*}{ [19] } \\
\hline & $\mathrm{R}$ & CCATTGTAGCACGTGTGTAGCC & \\
\hline \multirow{2}{*}{ Fungi } & $\mathrm{F}$ & GAGGAAGTAAAAGTCGTAACAAGGTTTC & \multirow{2}{*}{ [19] } \\
\hline & $\mathrm{R}$ & CAAATTCACAAAGGGTAGGATGATT & \\
\hline \multirow{2}{*}{ Protozoa } & $\mathrm{F}$ & GCTTTCGWTGGTAGTGTATT & \multirow{2}{*}[20]{} \\
\hline & $\mathrm{R}$ & CTTGCCCTCYAATCGTWCT & \\
\hline \multirow{2}{*}{ Methanogens } & $\mathrm{F}$ & TTCGGTGGATCDCARAGRGC & \multirow{2}{*}[20]{} \\
\hline & $\mathrm{R}$ & GBARGTCGWAWCCGTAGAATCC & \\
\hline \multirow{2}{*}{ B. fibrisolvens } & $\mathrm{F}$ & ACACACCGCCCGTCACA & \multirow{6}{*}{ [21] } \\
\hline & $\mathrm{R}$ & TCCTTACGGTTGGGTCACAGA & \\
\hline \multirow{2}{*}{ C.proteoclasticum } & $\mathrm{F}$ & TCCGGTGGTATGAGATGGGC & \\
\hline & $\mathrm{R}$ & GTCGCTGCATCAGAGTTTCCT & \\
\hline \multirow{2}{*}{ F. succinogenes } & $\mathrm{F}$ & GTTCGGAATTACTGGGCGTAAA & \\
\hline & $\mathrm{R}$ & CGCCTGCCCCTGAACTATC & \\
\hline \multirow{2}{*}{ R. albus } & $\mathrm{F}$ & CGGCAACGAGCGCAACCC & \multirow{2}{*}{ [22] } \\
\hline & $\mathrm{R}$ & CCATTGTAGCACGTGTGTAGCC & \\
\hline \multirow{2}{*}{ R. flavefaciens } & $\mathrm{F}$ & CGAACGGAGATAATTTGAGTTTACTTAGG & \multirow{2}{*}{ [23] } \\
\hline & $\mathrm{R}$ & CGGTCTCTGTATGTTATGAGGTATTACC & \\
\hline
\end{tabular}

\subsection{Denaturing Gradient Gel Electrophoresis (DGGE)}

A pair of general primers targeting bacterial V6-V8 regions were used to amplify the 16S rRNA of bacteria in ruminal fluids. The primers were: forward, 5' -CGC CCG GGG CGC GCC CCG GGC GGG GGG GCG GGG GCA CGG GGG GAA CGC GAA GAA CCT TAC-3' (underline means GC clamp); reverse, $5^{\prime}$-CGG TGT GTA CAA GAC CC-3'. The procedures for PCR were as follows: pre-denaturalization for $10 \mathrm{~min}$ at $94.0^{\circ} \mathrm{C}, 35$ cycles of denaturalization for $45 \mathrm{~s}$ at $94.0^{\circ} \mathrm{C}$, annealing for $45 \mathrm{~s}$ at $62.8^{\circ} \mathrm{C}$, extension for $45 \mathrm{~s}$ at $72.0^{\circ} \mathrm{C}$, followed by extension for $10 \mathrm{~min}$ at $72.0^{\circ} \mathrm{C}$.

Specific separation of PCR amplification products was performed by DGGE, as previously described [24]. Briefly, PCR-amplified samples were subjected to 7-h electrophoresis at $150 \mathrm{~V}$ through a $40 \%$ polyacrylamide gel at $60{ }^{\circ} \mathrm{C}$, and then were subjected to electrophoresis again through $40 \%$ to $60 \%$ denaturing gradient gel. After two electrophoreses, the gel was stained with SYBR Green I (Molecular Probes, St. Louis, MO, USA) for 30 min with $1 \times$ Tris-acetate-EDTA (ethylenediaminetetraacetic acid) (TAE) buffer. Then the grey values of the bands in the gel were examined using Quantity One software (ChemiDoc XRS+, Bio-Rad laboratories, Hercules, CA, USA). The dominant bands were cut off using a sterile scalpel and immersed in deionized water for $5 \mathrm{~h}$ at $37^{\circ} \mathrm{C}$ and $4{ }^{\circ} \mathrm{C}$ overnight, respectively. Then, one microliter of this sample was used as template to amplify the V6-V8 region of the 16S rDNA gene with PCR primers without GC clamps. After agarose electrophoresis, these PCR products were purified and inserted into $\mathrm{pMD}-18-\mathrm{T} @$ plasmids. The recombinant $\mathrm{pMD}-18-\mathrm{T}$ plasmids were transformed into DH5 $\alpha$ @ component cells. These positive transformed cells were extracted using a plasmid mini-kit (TIANGEN prep Mini Plasmid Kit, Beijing, China) according to the manufacturer's instructions.

\subsection{DNA Sequencing and Phylogenetic Tree Analysis}

The plasmid DNA mentioned above was sequenced by Invitrogen Biotechnology Co., Ltd. (Shanghai, China) and analyzed using the BLAST program (http://www.ncbi.nlm.nih.gov/blast) [24,25]. The sequence distance matrix for all pair wise sequence combinations was analyzed using MEGA 4.0.2 software with the neighbor-joining phylogenetic tree method. All 16S rRNA sequence reads have been submitted to the NCBI Genbank with the accession numbers of JF798509-JF798517.

\subsection{Statistical Analysis}

Data were expressed as LSMEANS (means obtained based on the Least Square Error Method) \pm SEM. The normality of data distribution was first assessed using the Shapiro-Wilk test. When necessary, 
data were logarithmically, or Box-Cox transformed to achieve normality. The Pearson correlation coefficient was used to analyze the correlations between the antioxidant indexes and milk yield. Student's t-test was performed to evaluate the differences of serum antioxidative indexes in non-HS and HS seasons and serum/ruminal antioxidative indexes between the control and experimental groups. $p<0.05$ was considered statistically significant. All the statistical analyses were performed using the SAS 8.1 software (SAS Institute, Cary, NC, USA).

\section{Results}

\subsection{THI Determination in Different Seasons}

To confirm the THI index in dairy farm in spring and summer, we recorded the THI in April and July (Figure 1). In April, the THI values ranged from 50.15 to 65.44. All the THI values were below the HS threshold of 68 [26], indicating the non-HS condition during April. In July, THI values varied from 76.96 to 90.28 , and the average THI at afternoon was 83.24. All the THI values were higher than the HS threshold of 68 . These data suggested that the dairy cows were under HS conditions in July.

A

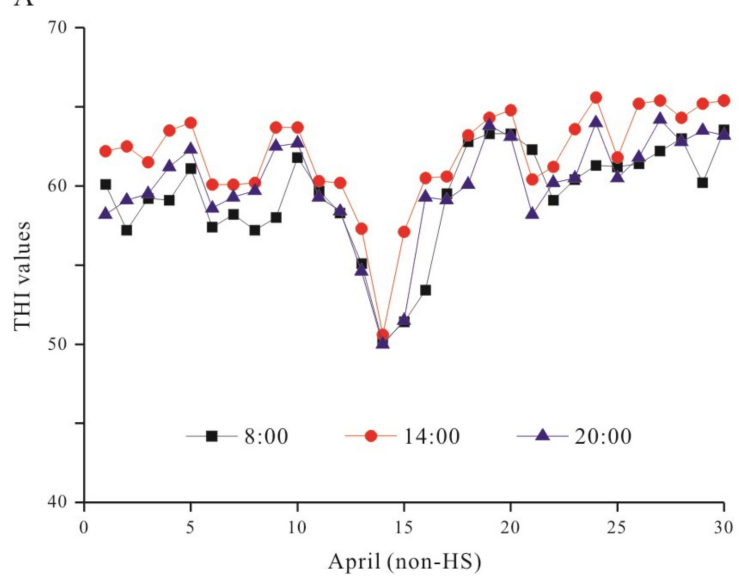

B

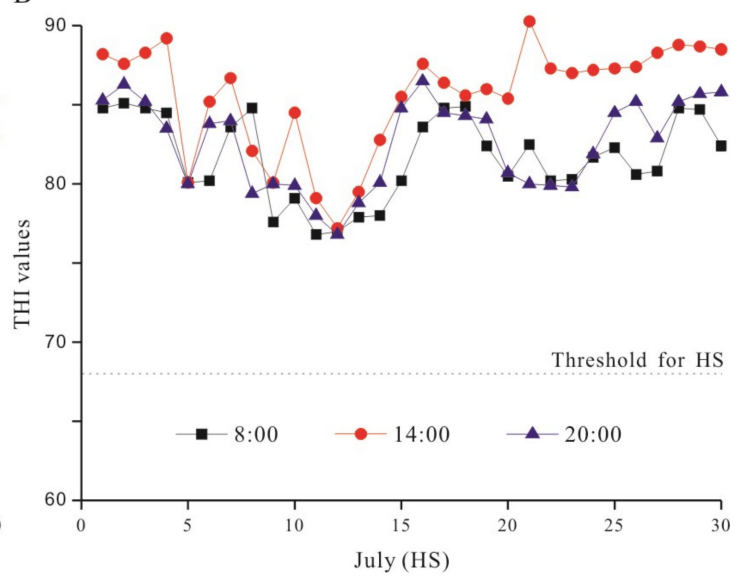

Figure 1. Temperature-humidity index (THI) values of the dairy barn in April and July. (A) Daily changes in THI values in the non-heat stress (HS) season (April); (B) Daily changes in THI values in the HS season (July). THI was recorded in the morning (08:00), afternoon (14:00), and night (20:00) each day. All the THI values were higher than the HS threshold of 68 in July.

\subsection{Changes in Serum Antioxidant Capacity of Dairy Cows in Spring (Non-HS) and Summer (HS)}

The serum antioxidant indexes of dairy cows in the non-HS season and HS season are shown in Figure 2. The results indicated that the four antioxidant indexes (SOD, GSH-Px, CAT, and T-AOC) in dairy cows under HS conditions were all significantly lower than those in non-HS season $(p<0.05)$. Consistently, the content of MDA in dairy cows under summer HS conditions was significantly increased, compared with that under non-HS conditions $(p<0.05)$, suggesting the accumulation of superoxidative anion radicals. These results indicated the reduction in antioxidant capacity under HS. Thus, these five antioxidant indexes could be the useful candidates to indicate HS in dairy cows. 


$$
\begin{aligned}
& \text { A } \\
& \stackrel{1}{1} \\
& \text { C }
\end{aligned}
$$
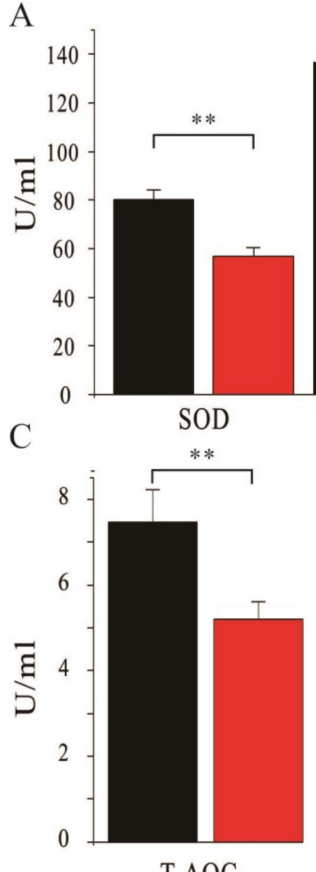

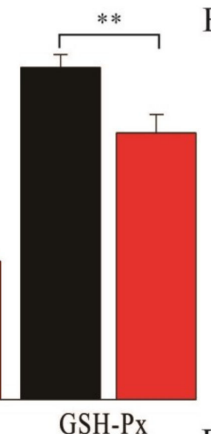

GSH-Px D
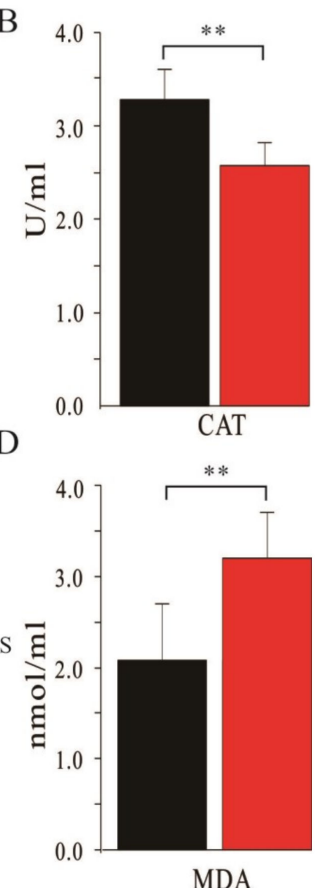

Figure 2. Serum antioxidant capacities of dairy cows in non-HS and HS season. All the 40 dairy cows were fed with standard diet. Blood samples were collected during spring (non-HS season) and summer (HS season), respectively. Superoxide dismutase (SOD) and glutathione peroxidase (GSH-Px) (A), catalase (CAT) (B), total antioxidation (T-AOC) (C), and malondialdehyde (MDA) (D) levels in the serum of dairy cows in non-HS and HS seasons. ${ }^{* *}: p<0.01$

\subsection{Correlation Analysis between the Serum Antioxidant Capacity and Milk Yield}

SOD, GSH-Px, and T-AOC showed negative correlations with the decrease rate of milk yield $(p<0.01)$ (Table 3). Meanwhile, MDA showed a significant positive correlation with the decrease rate of milk yield $(p<0.05)$. However, CAT showed no significant difference with the decrease rate of milk yield $(p>0.05)$. Based on these data, SOD, GSH-Px, T-AOC, and MDA were selected to indicate the antioxidant capacities of dairy cows.

Table 3. Correlation analysis between serum antioxidant capacity and the milk yield.

\begin{tabular}{ccc}
\hline \multirow{2}{*}{ Items } & \multicolumn{2}{c}{ Milk Yield Decrease } \\
\cline { 2 - 3 } & Correlation Coefficient (r Values) & $p$ Values \\
\hline SOD $(\mathrm{U} / \mathrm{mL})$ & -0.462 & $p<0.01$ \\
GSH-Px $(\mathrm{U} / \mathrm{mL})$ & -0.619 & $p<0.01$ \\
CAT $(\mathrm{U} / \mathrm{mL})$ & -0.291 & $p>0.05$ \\
T-AOC $(\mathrm{U} / \mathrm{mL})$ & -0.515 & $p<0.01$ \\
MDA $(\mathrm{nmol} / \mathrm{mL})$ & 0.371 & $p<0.05$ \\
\hline
\end{tabular}

\subsection{Effects of DHP on Serum Antioxidant Capacity of Dairy Cows under HS Conditions}

The effects of DHP on the dairy cow serum antioxidant indexes under HS conditions are shown in Figure 3. The values of SOD and GSH-Px in the experiment (S-D) group were significantly increased, compared with those in the control (S-ND) group $(p<0.01)$. DHP treatment favorably increased T-AOC level and decreased MDA level, but the changes in these two indexes were not statistically significant $(p>0.05)$. These data indicated that the addition of DHP in diet might enhance the antioxidant capacity of dairy cows under HS conditions. 
A

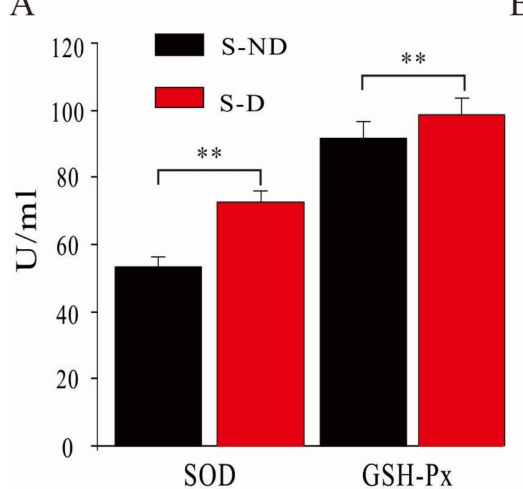

B

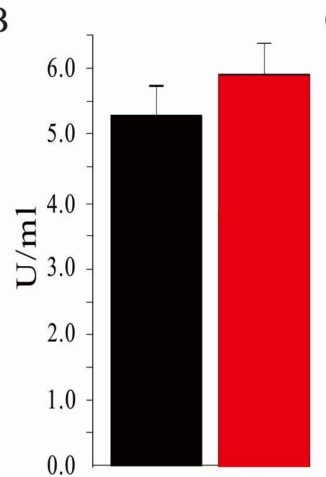

T-AOC
C

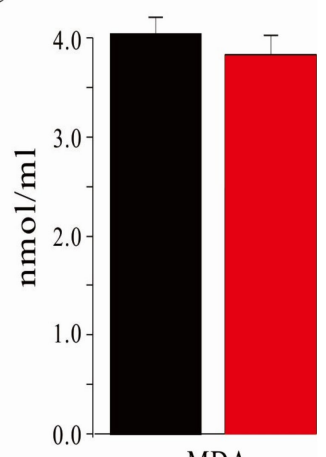

MDA

Figure 3. Effects of dihydropyridine (DHP) on serum antioxidative index. Twenty heat-sensitive dairy cows were divided into control (S-ND) group and experimental (S-D) group. The control group (S-ND) was fed with the standard diet. The experimental group (S-D) was fed with the standard diet containing $3 \mathrm{~g} /$ day/cow DHP. (A) Effects of DHP on serum SOD and GSH-Px concentration; (B) effects of DHP on serum T-AOC level; (C) effects of DHP on serum MDA content. ${ }^{* *}: p<0.01$.

\subsection{Effects of DHP on Ruminal Antioxidant Capacity of Dairy Cows under HS Condition}

The impacts of DHP on the ruminal antioxidant status on dairy cow are presented in Figure 4. Our results indicated that the addition of DHP to the diet significantly increased the concentrations of SOD, GSH-Px, and T-AOC in the experimental group $(p<0.01)$. These changes mean an enhanced ability to eliminate free radicals, peroxide, and $\mathrm{H} 2 \mathrm{O} 2$, thus alleviating the harmful effects of $\mathrm{HS}$ on the dairy cows. Similarly, the content of MDA, a toxic metabolic product, in the experimental group was significantly lower than that in the control group $(p<0.01)$, indicating an improved antioxidant capacity of dairy cows. Together, DHP addition in the diet significantly enhanced the ruminal antioxidant ability of dairy cows under HS conditions.

A

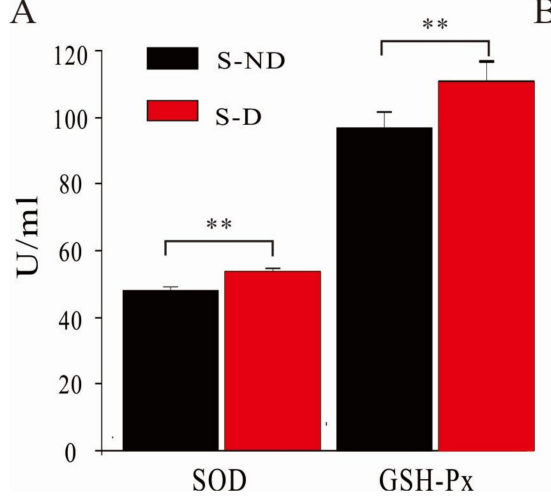

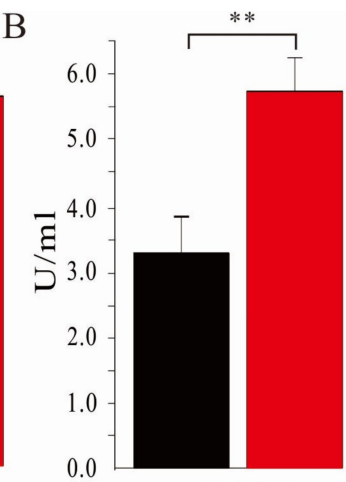

T-AOC

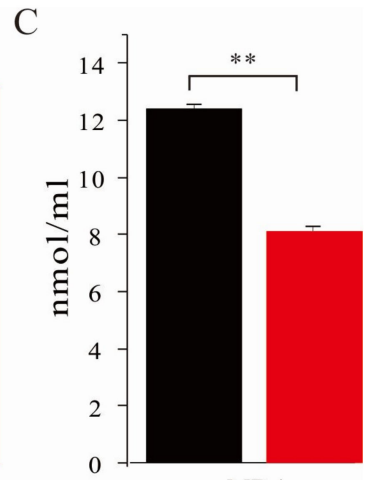

MDA

Figure 4. Effects of DHP on the ruminal antioxidative capacity of dairy cows under HS. Ruminal fluids were collected at 13:00 on 30 July and 07:00 and 10:00 on 31 July. (A) Effects of DHP on ruminal SOD and GSH-Px concentrations of dairy cows under HS; (B) effects of DHP on ruminal T-AOC level of dairy cows under HS; (C) effects of DHP on ruminal MDA concentration of dairy cows under HS. $* *: p<0.01$.

\subsection{Effects of DHP on Ruminal Microbial Communities}

The effects of DHP on ruminal microbial communities are shown in Figure 5. The contents of fungi, protozoa, B. fibrisolvens, and C.proteoclasticum in the experimental group were significantly higher than their counterparts in the control group $(p<0.01)$, whereas the content of methanogens in the experimental group was significantly lower than that of the control group $(p<0.01)$. However, the contents of cellulose-decomposing microbes, namely, F. succinogenes, R. albus, and R. flavefaciens 
exhibited no significant differences between the experimental group and the control group $(p>0.05)$. Taken together, the supplementation of DHP in the diet could alter the ruminal microbial communities in dairy cows.

A

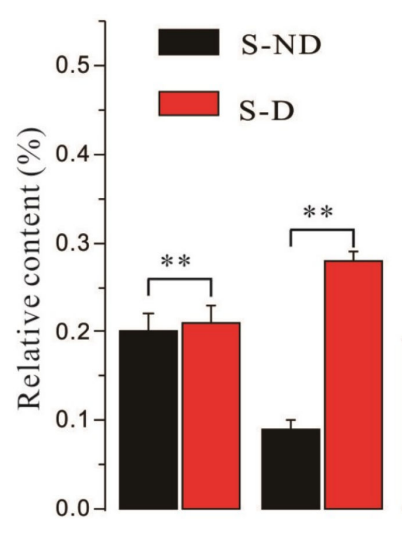

«ง
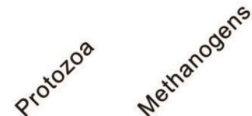
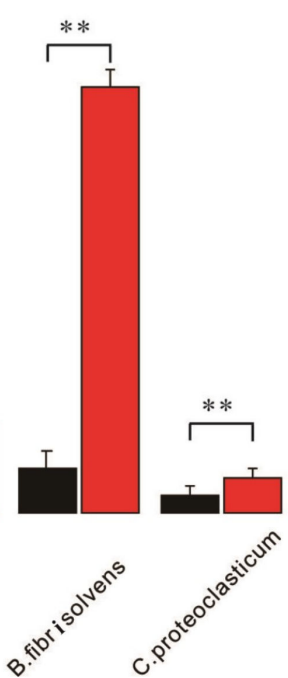

$\mathrm{B}$

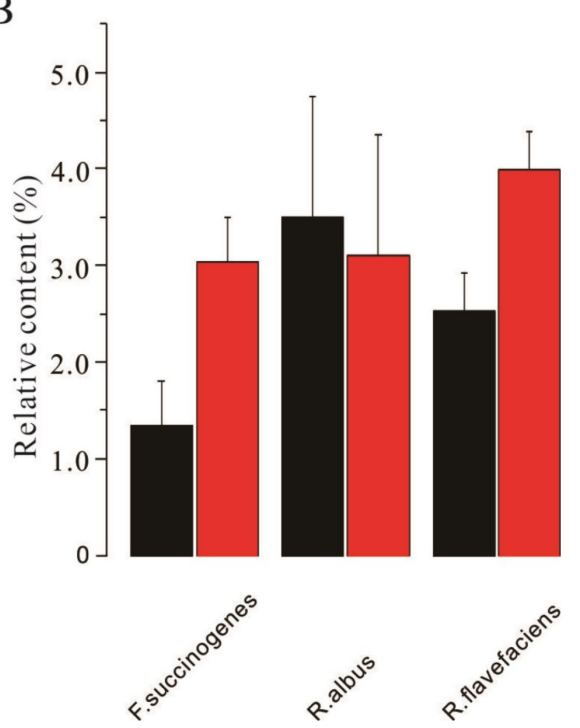

Figure 5. Effects of DHP on ruminal microbial communities in dairy cows. (A) Effects of DHP on the contents of fungi, protozoa, methanogens, B. fibrisolvens, and C.proteoclasticum in the rumen of dairy cows under HS conditions; (B) effects of DHP on the relative contents of F. succinogenes, R. albus, and $R$. flavefaciens in the rumen of dairy cows under HS conditions. ${ }^{* *}: p<0.01$

\subsection{DGGE Analysis of Microbe Communities in Rumen}

The ruminal microbial communities were further detected by DGGE (Figure 6). The profiles of individual cows in the same treatment group were relatively similar. For example, the similarity between lane two and lane three (respectively representing an individual cow) was higher than 95\% (Figure 6B), suggesting the similar composition of ruminal microbial community within the same group. However, the profiles greatly differed between the control group and the experimental group, although a small section of similarity was observed, indicating that the composition of the ruminal microbial community in the experimental group was different from that in the control group (Figure 6B,C). The bacteria derived from the rumen of dairy cows in control and experimental groups fell into mainly two clusters. The cluster derived from experimental group cows' rumen fluids showed a low similarity of $42 \%$ with the other cluster, suggesting a remarkable alteration in microbial community induced by DHP (Figure 6D). In general, the addition of DHP induced an increase in the number of the dominant microbes, suggesting more complex microbial communities in the dairy cows treated by DHP.

Twenty-eight bands in the Figure $6 \mathrm{C}$ were retrieved. The cluster analysis of the ruminal bacterial community is shown in Figure 6D and Table 4 . In the ruminal fluid samples, microbial communities fell into two main clusters. The DGGE profiles of cow eight and cow nine in the experimental group were clustered together, while the DGGE profiles of the other cows fell into the other cluster. The similarity between the two clusters was $42 \%$. Meanwhile, the similarities between individual cows within the same group varied from $42 \%$ to $87 \%$. After the amplification, cloning, and sequencing, thirty-two positive clones were selected from those dominant bands. These positive clones are highlighted with arrows in Figure 6B. After BLAST against the NCBI, the sequence information of these nine $16 \mathrm{~S}$ rRNAs were submitted to Genbank. Their accession numbers were JF798509-JF798517 (Table 5). These data indicated that the addition of DHP to the diet drastically altered the ruminal microbial community in the dairy cows. 


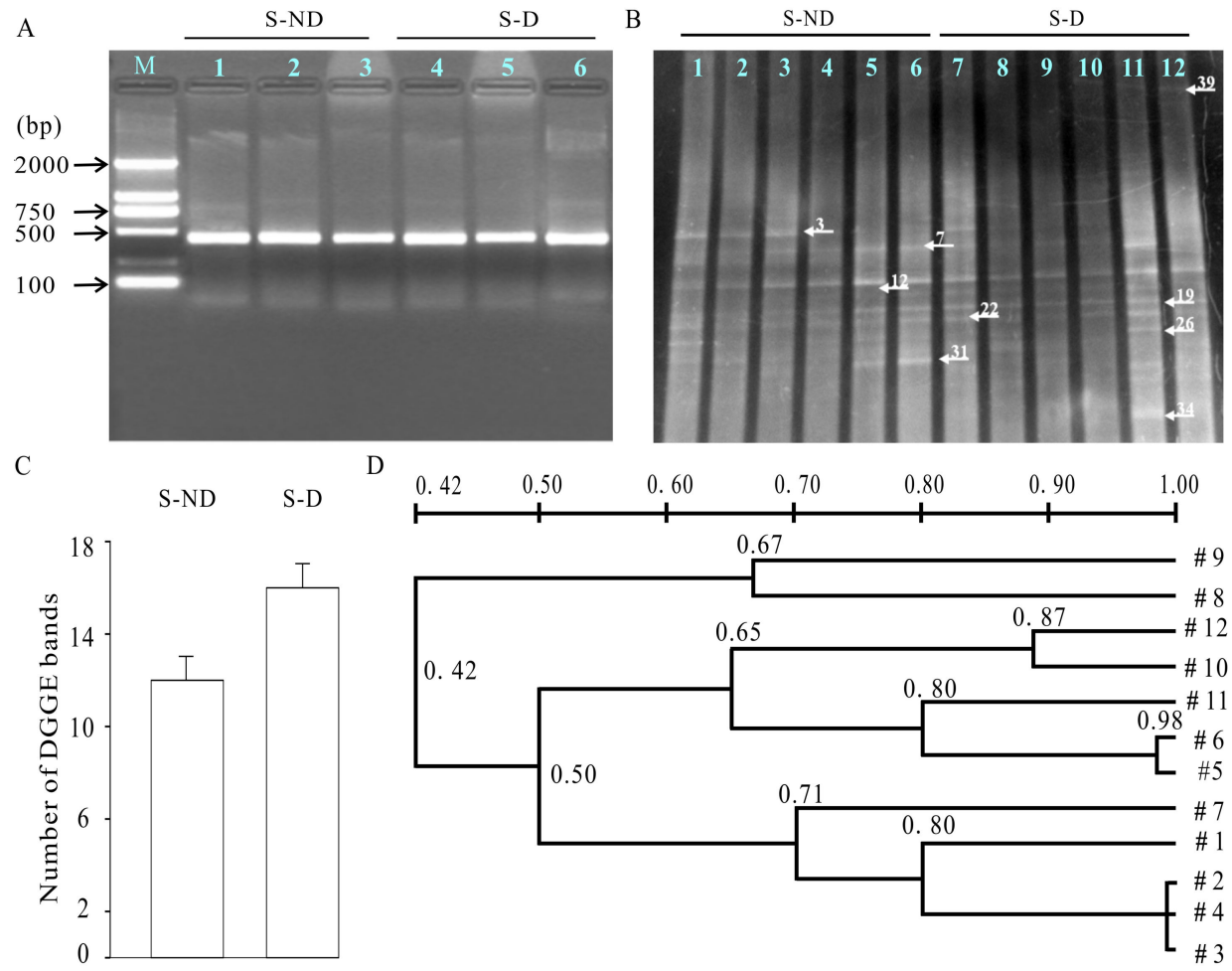

Figure 6. Effects of DHP on the ruminal bacterial community in dairy cows under HS conditions. (A) A representative agarose gel electrophoresis of rumen bacteria PCR products. Lanes 1-3 indicate electrophoresis results of PCR products from three different cows in the control group; lanes 4-6 indicate the electrophoresis results of three different cows in experimental group; M: DL2000 DNA marker. (B) Lanes 1-6 indicate the denaturing gradient gel electrophoresis (DGGE) results of PCR products from six different cows in the control group; lanes 7-12 indicate the DGGE results of PCR products from six different cows in the experimental group. Arrows indicate the bands of PCR products; $(C)$ the number of DGGE bands in control group (S-ND) and the experimental group (S-D); (D) cluster analysis of the ruminal bacterial community between control group and experimental group.

Table 4. Similarities in rumen bacterial community between control group and experimental group.

\begin{tabular}{ccccccccccccc}
\hline Lane & $\mathbf{1}$ & $\mathbf{2}$ & $\mathbf{3}$ & $\mathbf{4}$ & $\mathbf{5}$ & $\mathbf{6}$ & $\mathbf{7}$ & $\mathbf{8}$ & $\mathbf{9}$ & $\mathbf{1 0}$ & $\mathbf{1 1}$ & $\mathbf{1 2}$ \\
\hline 1 & 100.0 & 80.1 & 79.8 & 80.3 & 69.2 & 70.8 & 60.5 & 40.1 & 20.0 & 19.2 & 52.9 & 32.7 \\
2 & 80.1 & 100.0 & 99.3 & 99.3 & 68.2 & 68.4 & 74.8 & 50.1 & 24.9 & 24.0 & 62.4 & 40.3 \\
3 & 79.8 & 99.3 & 100.0 & 99.3 & 68.3 & 68.5 & 74.2 & 50.0 & 24.9 & 24.0 & 62.5 & 40.4 \\
4 & 80.3 & 99.3 & 99.3 & 100.0 & 68.1 & 68.3 & 74.7 & 49.6 & 24.8 & 23.9 & 62.3 & 40.2 \\
5 & 69.2 & 68.2 & 68.3 & 68.1 & 100.0 & 98.4 & 50.8 & 50.6 & 34.3 & 55.1 & 80.4 & 67.6 \\
6 & 70.8 & 68.4 & 68.5 & 68.3 & 98.4 & 100.0 & 50.9 & 50.7 & 34.3 & 55.0 & 80.3 & 67.5 \\
7 & 60.5 & 74.8 & 74.2 & 74.7 & 50.8 & 50.9 & 100.0 & 49.8 & 24.8 & 23.9 & 46.4 & 40.2 \\
8 & 40.1 & 50.1 & 50.0 & 49.6 & 50.6 & 50.7 & 49.8 & 100.0 & 67.2 & 47.7 & 47.1 & 41.0 \\
9 & 20.0 & 24.9 & 24.9 & 24.8 & 34.3 & 34.3 & 24.8 & 67.2 & 100.0 & 72.1 & 46.9 & 61.6 \\
10 & 19.2 & 24.0 & 24.0 & 23.9 & 55.1 & 55.0 & 23.9 & 47.7 & 72.1 & 100.0 & 66.6 & 87.2 \\
11 & 52.9 & 62.4 & 62.5 & 62.3 & 80.4 & 80.3 & 46.4 & 47.1 & 46.9 & 66.6 & 100.0 & 77.4 \\
12 & 32.7 & 40.3 & 40.4 & 40.2 & 67.6 & 67.5 & 40.2 & 41.0 & 61.6 & 87.2 & 77.4 & 100.0 \\
\hline
\end{tabular}

Note: lanes 1-6 mean the DGGE profiles of six cows from control group; lane 7-12 mean the DGGE profiles of six cows from experimental group. 
Table 5. Detailed information of rumen bacterial $16 \mathrm{~S}$ rDNA clones.

\begin{tabular}{|c|c|c|c|c|c|}
\hline Bands & Closest Known Species & $\begin{array}{l}\text { Sequence } \\
\text { Similarity }\end{array}$ & $\begin{array}{l}\text { Length } \\
\text { (bp) }\end{array}$ & Taxonomic Group & Acc. Number \\
\hline B3 & $\begin{array}{l}\text { Lachnospira pectinoschiza } \\
\text { AY699277.1 }\end{array}$ & $99 \%$ & 433 & Bacteria; Firmicutes; Clostridia; Clostridiales; Lachnospiraceae; Lachnospira. & JF798509 \\
\hline B7 & $\begin{array}{l}\text { Lysobacter brunescens } \\
\text { GQ859167.1 }\end{array}$ & $99 \%$ & 434 & $\begin{array}{c}\text { Bacteria; Proteobacteria; Gammaproteobacteria; Xanthomonadales; } \\
\text { Xanthomonadaceae; Lysobacter. }\end{array}$ & JF798510 \\
\hline B12 & $\begin{array}{l}\text { Acinetobacter sp. JFAN2 } \\
\text { HQ693555.1 }\end{array}$ & $99 \%$ & 435 & $\begin{array}{c}\text { Bacteria; Proteobacteria; Gammaproteobacteria; Pseudomonadales; } \\
\text { Moraxellaceae; Acinetobacter. }\end{array}$ & JF798511 \\
\hline B19 & $\begin{array}{l}\text { Anoxybacillus sp. IP-3 } \\
\text { AB618500.1 }\end{array}$ & $99 \%$ & 436 & Bacteria; Firmicutes; Bacillales; Bacillaceae; Anoxybacillus. & JF798512 \\
\hline B22 & $\begin{array}{l}\text { Pseudomonas sp. SUT } 19 \\
\text { HM446471.1 }\end{array}$ & $99 \%$ & 434 & $\begin{array}{c}\text { Bacteria; Proteobacteria; Gammaproteobacteria; Pseudomonadales; } \\
\text { Pseudomonadaceae; Pseudomonas. }\end{array}$ & JF798513 \\
\hline B26 & $\begin{array}{l}\text { Uncultured bacterium } \\
\text { EU843886.1 }\end{array}$ & $99 \%$ & 437 & Bacteria; environmental samples & JF798514 \\
\hline B31 & $\begin{array}{l}\text { Pseudomonas sp. SUT } 19 \\
\text { HM446471.1 }\end{array}$ & $99 \%$ & 434 & $\begin{array}{c}\text { Bacteria; Proteobacteria; Gammaproteobacteria; Pseudomonadales; } \\
\text { Pseudomonadaceae; Pseudomonas. }\end{array}$ & JF798515 \\
\hline B34 & $\begin{array}{l}\text { Tepidimonas aquatica } \\
\text { NR_025755.1 }\end{array}$ & $99 \%$ & 430 & Bacteria; Proteobacteria; Betaproteobacteria; Burkholderiales; Tepidimonas. & JF798516 \\
\hline B39 & $\begin{array}{l}\text { Xanthomonas axonopodis } \\
\text { AB101447.1 }\end{array}$ & $99 \%$ & 433 & $\begin{array}{c}\text { Bacteria; Proteobacteria; Gammaproteobacteria; Xanthomonadales; } \\
\text { Xanthomonadaceae; Xanthomonas. }\end{array}$ & JF798517 \\
\hline
\end{tabular}




\subsection{Phylogenic Tree Analysis}

Based on the information of 16S rRNA sequences, a phylogeny tree was constructed using the neighbor-joining method (Figure 7). The nine dominant bacteria in ruminal fluids were identified, including Lachnospira pectinoschiza(AY699277.1), Lysobacter brunescens(GQ859167.1), Acinetobacter sp. JFAN2 (HQ693555.1), Anoxybacillus sp. IP-3 (AB618500.1), Pseudomonas sp. SUT 19 (HM446471.1), Pseudomonas sp. SUT 19 (HM446471.1), Tepidimonas aquatic (NR_025755.1), Xanthomonas axonopodis (AB101447.1), and a uncultured bacterium (EU843886.1) (Table 5).

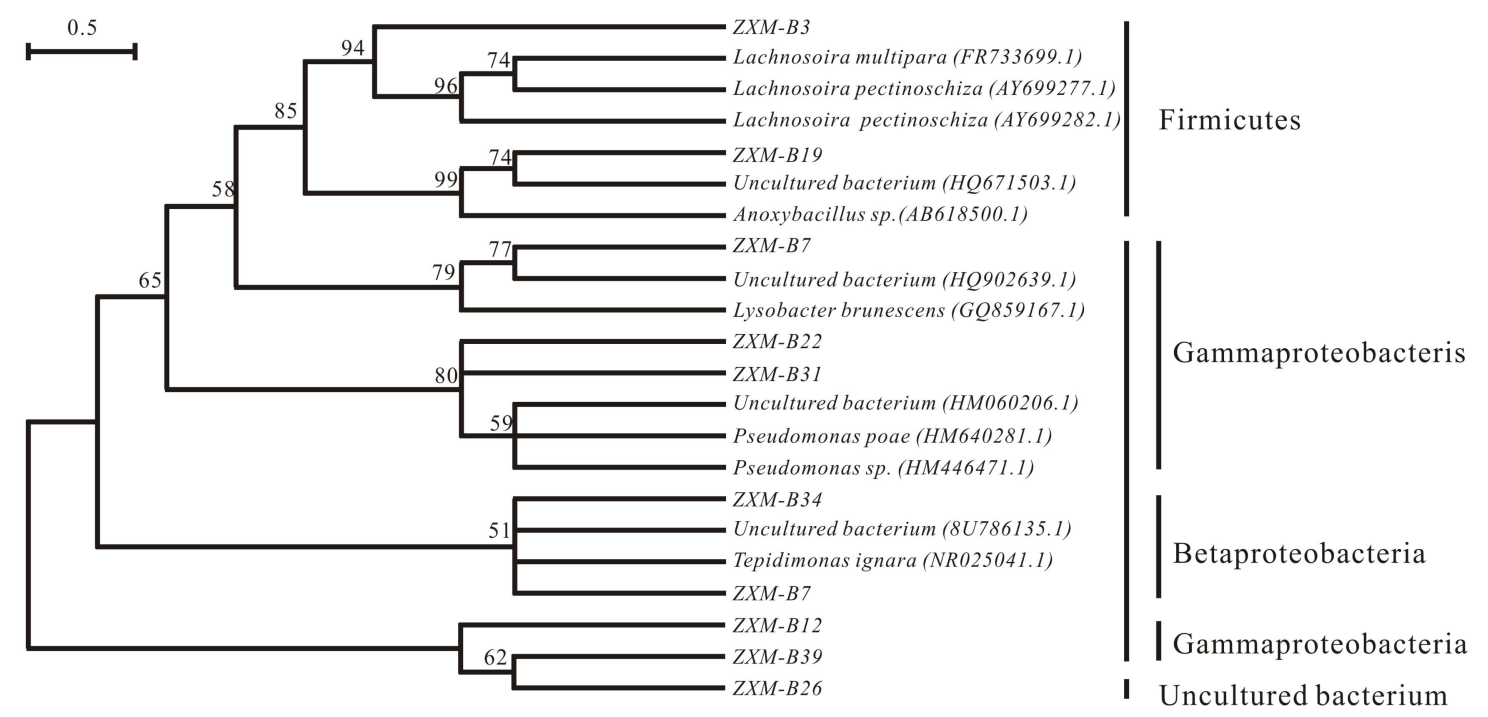

Figure 7. Phylogenic tree of rumen bacteria.

\section{Discussion}

The present study mainly explored the effects of DHP addition to the diet on the antioxidant capacity and ruminal microbial communities in lactating dairy cows. The results demonstrated that DHP addition enhanced the antioxidant capacities both in the serum and rumen. Meanwhile, DHP addition altered the compositions of the ruminal microbial community in dairy cows. These data indicated that DHP addition to the diet helped to relieve the negative effects of HS on dairy cows.

This experiment was carried out in the Yangtze River Dairy Co. Ltd. in Wuhu (Wuhan, China). In order to monitor HS, the temperature, humidity, and THI were analyzed in April and July (Figure 1). The results demonstrated that the minimal value of THI in July was 76.96, which exceeded the threshold of HS of 68.0 [26]. The level of HS to which the dairy cows were exposed was affected by effective temperature which included five environmental factors, namely, air temperature, humidity, air movement, solar radiation, and precipitation. However, only temperature and humidity were set as variables in the simple THI method which was effective and efficient in evaluating the effects of HS on dairy cows. For example, one previous study reported that the average daily milk yield decreased approximately $0.2 \mathrm{~kg}$ per unit increase in THI, when THI $\geq 72$ [27]. The high THI values in July observed in this experiment suggest that the dairy cows were possibly under HS conditions.

In the hot and humid summer, both the rapid increase in temperature and humidity resulted in the occurrence of HS, which can decrease milk yield in dairy cows. The decreased milking performance was partly due to the reduction in the antioxidant capacity of dairy cows. Therefore, we first analyzed the correlation between the most commonly used antioxidant indexes and the decreased rate of milk yield. The correlation analysis suggested that SOD, GSH-Px, T-AOC $(p<0.01)$, and MDA $(p<0.05)$ showed significant correlation with the reduced milking ability (Table 3). These four correlated indexes were further analyzed to determine the effects of DHP on dairy cows. In addition, twenty heat-sensitive cows were selected and used in the subsequent experiment. 
Daily metabolic activities in dairy cows produce a lot of free radicals and other bioactive substances [5]. Under HS conditions, the antioxidant ability of the blood in the dairy cows is decreased, while the expression of inflammation factors is increased. These changes will result in tissue damage and inflammation [1]. As shown in Figures 3 and 4, the addition of DHP significantly increased the activities of SOD, GSH-Px in blood and ruminal fluids and the activities of T-AOC in ruminal fluids $(p<0.01)$. Our data demonstrated that DHP addition in the diet improved the antioxidant capacity in dairy cows. Furthermore, the significantly decreased MDA level in the experimental group indicated that DHP addition in the diet decreased the toxic metabolic products in the dairy cows $(p<0.01)$. Blood samples collected before the start of the experiment using as a covariant during both non-HS and HS seasons will enhance the scientificity and rigorousness of the experimental design. Taken together, the results indicate that the addition of DHP in the diet can partly reverse the harmful effects of HS on the dairy cows.

In the rumen, a high anaerobic environment, the microbes are more sensitive to free radicals and oxidative stresses induced by external environment changes. Wang et al. in 2010 reported that unsaturated fatty acids in the diet led to oxidative stress which was harmful to the growth of rumen cellulolytic bacteria [28]. This harmful effect can be reversed by antioxidants such as vitamin $\mathrm{E}$ which can also improve the stability of high-fat feed [29]. This report is in line with our observations of antioxidant capacities in the sera and ruminal fluids of DHP-treated dairy cows (Figures 2 and 3). Similarly, Vazquez et al. (2008) reported that feeding Agrado Plus, a type of mixed antioxidant, improved lactation performance and the antioxidant status of the cow [30]. However, the responses of ruminal microbes to different substances such as fat, Agrado Plus, and DHP differed depending on many variables. However, the underlying mechanisms of these responses were unclear and remained to be further investigated.

Stresses were harmful to rumen fermentation and the growth of rumen microbes [31]. HS significantly resulted in the decrease in most types of rumen microbes such as Methanobacteria, R. albus, F. succinogenes and fungi. In our study, DHP treatment resulted in the occurrence of some new bands and the disappearance of some bands, but the total number of bands was increased (Figure 6). Our results demonstrated that the decrease in rumen microbes could be reversed by DHP addition, suggesting that DHP altered the structure and component of rumen bacteria in dairy cows. Unexpectedly, the amount of the Methanobacteria decreased after DHP treatment, which might be due to the reduction in two types of methane-synthesizing materials (acetic acid and hydrogen). On the one hand, the content of acetic acid decreased under HS conditions. On the other hand, DHP increased the number of hydrogen-related microorganisms such as B. fibrisolvens and C.proteoclasticum, which consumed a lot of hydrogen. Therefore, the growth of Methanobacteria was inhibited, thus leading to the reduced methane production [32]. These data suggested that DHP could significantly alter the structure and component of rumen microbes, in turn affecting the fermentation mode in the rumen of dairy cows.

Many rumen bacteria can be analyzed only by using molecular biological techniques such as RT-PCR and DGGE due to their specific nutritional requirements. Our phylogenetic tree results of rumen bacteria demonstrated that most rumen bacteria belonged to Proteobacteria and Firmicutes. Some bacteria such as band three Lachnospira mainly appeared in the control group, while other bacteria such as band seven Xanthomonadaceae mainly appeared in the experimental group. In addition, some bacteria such as band 12 Acinetobacter, band 19 Anoxybacillus, and band 26 an unknown bacterium could be detected with or without DHP. Taken together, DHP could enhance the diversity of rumen bacteria. Particularly, it can promote the growth of bacteria Xanthomonadaceae and Xanthomonas. In summary, DHP addition in the diet is helpful for improving the ruminal microbe biodiversity and increasing the antioxidant capabilities of dairy cows under HS conditions. These beneficial effects can improve the health status of dairy cows, in turn facilitating an increase in milk yield. However, the effects of DHP on the metabolism, blood physiochemical characteristics, and physiological connections among these antioxidant indexes remain to be further investigated. 


\section{Conclusions}

Addition of DHP in lactating dairy cow diet enhances the antioxidative capacity and improves composition of dairy cow ruminal microbiota under HS. DHP additives may be a useful way to rescue dairy cows from HS, which would benefit the dairy cow industry.

Author Contributions: Conceptualization, methodology, data analyzes and manuscript draft by M.-F.Y., X.-M.Z., H.C.; Experimental design and manuscript revision by J.-M.Y. and G.-H.H. All authors have read and agreed to the published version of the manuscript.

Funding: This research was funded by National Key Research and Development Program of China (No. 2016YFD0500507; 2017YFD0501903).

Acknowledgments: The authors thank Ping Liu (College of Foreign Languages, Huazhong Agricultural University) for English language editing of this paper.

Conflicts of Interest: The authors declare no conflict of interest. The funders had no role in the design of the study; in the collection, analyses, or interpretation of data; in the writing of the manuscript, or in the decision to publish the results.

\section{References}

1. Aitken, S.; Karcher, E.; Rezamand, P.; Gandy, J.; VandeHaar, M.; Capuco, A.; Sordillo, L. Evaluation of antioxidant and proinflammatory gene expression in bovine mammary tissue during the periparturient period. J. Dairy Sci. 2009, 92, 589-598. [CrossRef] [PubMed]

2. Gao, S.; Guo, J.; Quan, S.; Nan, X.; Sanz-Fernandez, M.V.; Baumgard, L.; Bu, D. The effects of heat stress on protein metabolism in lactating Holstein cows. J. Dairy Sci. 2017, 100, 5040-5049. [CrossRef] [PubMed]

3. Zachut, M.; Kra, G.; Livshitz, L.; Portnick, Y.; Yakoby, S.; Friedlander, G.; Levin, Y. Seasonal heat stress affects adipose tissue proteome toward enrichment of the Nrf2-mediated oxidative stress response in late-pregnant dairy cows. J. Proteom. 2017, 158, 52-61. [CrossRef] [PubMed]

4. Gantner, V.; Bobic, T.; Gantner, R.; Gregic, M.; Kuterovac, K.; Novakovic, J.; Potocnik, K. Differences in response to heat stress due to production level and breed of dairy cows. Int. J. Biometeorol. 2017, 92, 1675-1685. [CrossRef] [PubMed]

5. Puppel, K.; Kapusta, A.; Kuczyńska, B. The etiology of oxidative stress in the various species of animals, a review. J. Sci. Food Agric. 2014, 95, 2179-2184. [CrossRef] [PubMed]

6. Zheng, J.; Sun, L.; Shu, S.; Zhu, K.; Xu, C.; Wang, J.; Wang, H. Nuclear magnetic resonance-based serum metabolic profiling of dairy cows with footrot. J. Veter-Med Sci. 2016, 78, 1421-1428. [CrossRef] [PubMed]

7. Liang, J.-C.; Chen, H.-R.; Chiu, C.-C.; Liou, S.-F.; Chen, I.-J.; Yeh, J.-L. Protective effect of labedipinedilol-A, a novel dihydropyridine-type calcium channel blocker, on myocardial apoptosis in ischemia-reperfusion injury. Life Sci. 2006, 79, 1248-1256. [CrossRef]

8. Wang, J.-G.; Kario, K.; Lau, T.; Wei, Y.Q.; Park, C.G.; Kim, C.H.; Huang, J.; Zhang, W.; Li, Y.; Yan, P.; et al. Use of dihydropyridine calcium channel blockers in the management of hypertension in Eastern Asians: A scientific statement from the Asian Pacific Heart Association. Hypertens. Res. 2011, 34, 423-430. [CrossRef] [PubMed]

9. Robles, N.R.; Fici, F.; Grass1, G. Dihydropyridine calcium channel blockers and renal disease. Hypertens. Res. 2016, 40, 21-28. [CrossRef]

10. Wu, G. Important roles of dietary taurine, creatine, carnosine, anserine and 4-hydroxyproline in human nutrition and health. Amino Acids 2020, 52, 329-360. [CrossRef]

11. Niu, Z.; Liu, F.; Min, Y.; Li, W. Effects of dietary dihydropyridine supplementation on growth performance and lipid metabolism of broiler chickens. Czech J. Anim. Sci. 2010, 55, 116-122. [CrossRef]

12. Bian, L.Q.; Yuan, D.; Liu, X.J.; Chen, J.; Liao, S.W.; Li, L. Effects of dihydropyridine on the growth performance, meat quality and anti-oxidant properties of muslce tissues in fattening pigs. Henan J. Anim. Husban Vet. Med. 2010, 30, 5-7. [CrossRef]

13. West, J.; Mullinix, B.; Bernard, J. Effects of Hot, Humid Weather on Milk Temperature, Dry Matter Intake, and Milk Yield of Lactating Dairy Cows. J. Dairy Sci. 2003, 86, 232-242. [CrossRef]

14. Ministry of Agriculture of China. Veterinary Drug Quality Standards; China Agriculture Press: Beijing, China, 2003; pp. 1-2. 
15. Guo, J.; Gao, S.; Quan, S.; Zhang, Y.; Bu, D.; Wang, J. Blood amino acids profile responding to heat stress in dairy cows. Asian-Australas. J. Anim. Sci. 2017, 31, 47-53. [CrossRef]

16. Weimer, P.; Waghorn, G.; Odt, C.; Mertens, D. Effect of Diet on Populations of Three Species of Ruminal Cellulolytic Bacteria in Lactating Dairy Cows. J. Dairy Sci. 1999, 82, 122-134. [CrossRef]

17. Jin, D.; Zhao, S.; Zheng, N.; Bu, D.; Beckers, Y.; Wang, J. Urea nitrogen induces changes in rumen microbial and host metabolic profiles in dairy cows. Livest. Sci. 2018, 210, 104-110. [CrossRef]

18. Jafari, S.; Ebrahimi, M.; Meng, G.Y.; Rajion, M.A.; Jahromi, M.F. Dietary supplementation of papaya (Carica papaya 1.) leaf affects abundance of Butyrivibrio fibrisolvens and modulates biohydrogenation of $\mathrm{C} 18$ polyunsaturated fatty acids in the rumen of goats. Ital. J. Anim. Sci. 2017, 17, 326-335. [CrossRef]

19. Denman, S.E.; McSweeney, C.S. Development of a real-time PCR assay for monitoring anaerobic fungal and cellulolytic bacterial populations within the rumen. FEMS Microbiol. Ecol. 2006, 58, 572-582. [CrossRef]

20. Denman, S.E.; Tomkins, N.W.; McSweeney, C.S. Quantitation and diversity analysis of ruminal methanogenic populations in response to the antimethanogenic compound bromochloromethane. FEMS Microbiol. Ecol. 2007, 62, 313-322. [CrossRef]

21. Alekkhahi, M.; Tahmasbi, A.; Naserian, A.A.; Mesgaran, M.D.; Kleen, J.; AlZahal, O.; Ghaffari, M. Effects of supplementation of active dried yeast and malate during sub-acute ruminal acidosis on rumen fermentation, microbial population, selected blood metabolites, and milk production in dairy cows. Anim. Feed. Sci. Technol. 2016, 213, 29-43. [CrossRef]

22. Zhang, T.; Kucharzyk, K.H.; Kim, B.; Deshusses, M.A.; Hsu-Kim, H. Net Methylation of Mercury in Estuarine Sediment Microcosms Amended with Dissolved, Nanoparticulate, and Microparticulate Mercuric Sulfides. Environ. Sci. Technol. 2014, 48, 9133-9141. [CrossRef] [PubMed]

23. Agarwal, N.; Kamra, D.N.; Chatterjee, P.N.; Kumar, R.; Chaudhary, L.C. In vitro Methanogenesis, Microbial Profile and Fermentation of Green Forages with Buffalo Rumen Liquor as Influenced by 2-Bromoethanesulphonic Acid. Asian-Australas. J. Anim. Sci. 2008, 21, 818-823. [CrossRef]

24. Ma, L.; He, F.; Huang, T.; Zhou, Q.; Zhang, Y.; Wu, Z. Nitrogen and phosphorus transformations and balance in a pond-ditch circulation system for rural polluted water treatment. Ecol. Eng. 2016, 94, 117-126. [CrossRef]

25. Wang, W.; Li, C.; Li, F.; Wang, X.; Zhang, X.; Liu, T.; Nian, F.; Yue, X.; Li, F.; Pan, X.; et al. Effects of early feeding on the host rumen transcriptome and bacterial diversity in lambs. Sci. Rep. 2016, 6, 32479. [CrossRef] [PubMed]

26. Zimbelman, R.; Rhoads, R.; Rhoads, M.; Duff, G.; Baumguard, L.; Collier, R. A re-evaluation of the impact of temperature humidity index (THI) and black globe humidity index (BGHI) on milk production in high producing dairy cows. In Proceedings of the 24th Annu. Southwest Nutrition Management Conference, Tempe, AZ, USA, 26-27 February 2009; pp. 158-169.

27. Ravagnolo, O.; Misztal, I.; Hoogenboom, G. Genetic Component of Heat Stress in Dairy Cattle, Development of Heat Index Function. J. Dairy Sci. 2000, 83, 2120-2125. [CrossRef]

28. Wang, Y.-M. Effects of Diatery Fat and Engergy Density on Oxidative Stress and Lactation Performance in Dairy Cows, in the Absence or Presence of Antioxidant. Ph.D Thesis, Zhejiang University, Hangzhou, China, 2010.

29. Gobert, M.; Gruffat, D.; Habeanu, M.; Parafita, E.; Bauchart, D.; Durand, D. Plant extracts combined with vitamin $\mathrm{E}$ in PUFA-rich diets of cull cows protect processed beef against lipid oxidation. Meat Sci. 2010, 85, 676-683. [CrossRef] [PubMed]

30. Vazquez-Anon, M.; Nocek, J.; Bowman, G.; Hampton, T.; Atwell, C.; Vázquez, P.; Jenkins, T. Effects of Feeding a Dietary Antioxidant in Diets with Oxidized Fat on Lactation Performance and Antioxidant Status of the Cow. J. Dairy Sci. 2008, 91, 3165-3172. [CrossRef] [PubMed]

31. Polsky, L.; Von Keyserlingk, M. Invited review: Effects of heat stress on dairy cattle welfare. J. Dairy Sci. 2017, 100, 8645-8657. [CrossRef]

32. Miron, J.; Ben-Ghedalia, D.; Morrison, M. Invited Review: Adhesion Mechanisms of Rumen Cellulolytic Bacteria. J. Dairy Sci. 2001, 84, 1294-1309. [CrossRef]

(C) 2020 by the authors. Licensee MDPI, Basel, Switzerland. This article is an open access article distributed under the terms and conditions of the Creative Commons Attribution (CC BY) license (http://creativecommons.org/licenses/by/4.0/). 